\title{
The economic assessment of heavy dump trucks energy distribution while in operation at Kuzbass open-pit mines
}

\author{
Ilya Kuznetsov ${ }^{1 *}$, Ivan Panachev ${ }^{1}$, Georgiy Shirokolobov ${ }^{1}$, and Roman Dobrinin ${ }^{1}$ \\ ${ }^{1}$ T. F. Gorbachev Kuzbass State Technical University, 650000, Kemerovo, 28 Vesennyaya St., the \\ Russian Federation
}

\begin{abstract}
The monitoring results of quarry vehicles operation at Kuzbass open-pits are presented in the article. The factors influencing the transportation process energy intensity, as well as the economic efficiency of heavy dump trucks distribution in the conditions of a developed deposit are established. The dependences of changes in the specific energy consumption of dump trucks of different load capacities on the variation of the longitudinal slopes of the route are determined. The scheme of the energy distribution of the open-pit machines depending on the slope of the technological road on the rise is presented. Formulae for calculating the economic assessment of the operation of open-pit trucks of various load capacities in the conditions of an open-pit are given. The dependence of direct losses and downtime of BelAZ-7555, BelAZ-75131 and BelAZ-75306 dump trucks on the change in the longitudinal slope of the highway at the Kuzbass open-pits is established. Graphics of the relationship between direct losses from downtime of open-pit vehicles and the specific energy costs for transporting the blasted rock mass are obtained.
\end{abstract}

\section{Introduction}

The open-pit mining is a system of complex technical, technological and economic processes. Often, the main stages are distinguished as following: drilling, blasting, excavation, transportation [1].

The most expensive process is the transport systems operation for blasted rock mass transportation. The estimation of operating and capital costs is calculated using the generalized formulae that are generally accepted. In addition to resource and labour costs, it is also necessary to take into account energy costs when transporting the blasted rock mass [3].

One of the main tasks in production is the optimal distribution of heavy dump trucks through the parts of an open-pit, due to the road transport will have minimal losses or costs with maximum earnings.

The purpose of this work is to improve the methodology of technical and economic indicators assessment of the heavy dump trucks operation, using the methods of probable statistics and analytics.

\footnotetext{
${ }^{*}$ Corresponding author: kiv.sm@kuzstu.ru
} 


\section{Results and Discussions}

\subsection{Energy intensity of heavy dump trucks operation at Kuzbass mines}

Today the automobile fleet of Kuzbass open pits is represented by dump trucks of the "BelAZ" manufacturer (Fig. 1).

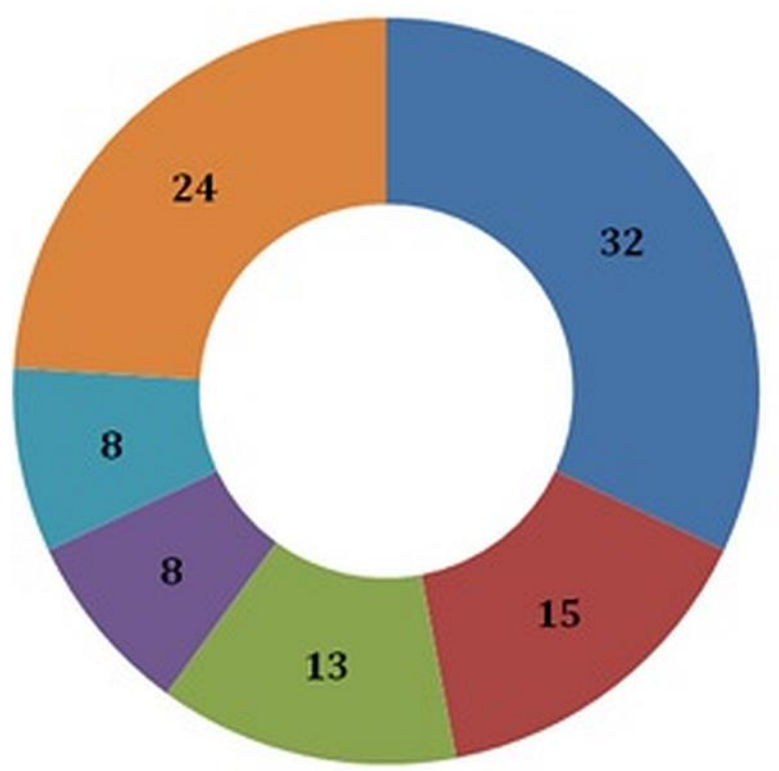

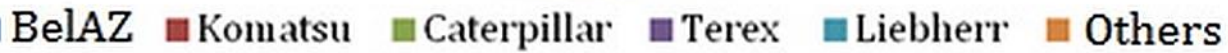

Fig. 1. The state of the dump truck fleet at Kuzbass open pits (percentage)

Energy intensity is a system of actions, because of which energy costs are rational or irrational. Therefore, the energy intensity can be represented in the form of detailed estimation of transport complexes operation [5].

For the energy estimation of rock mass transportation using heavy dump trucks, the value of the specific energy costs $(\mathrm{g} . \mathrm{s} . \mathrm{f} . / \mathrm{t} \cdot \mathrm{m})$ for the transportation of 1 ton is accepted. It is established that the specific energy consumption is significantly affected by such indicators as car overloading, the slope of the route on the rise, and others (Fig. 2). 


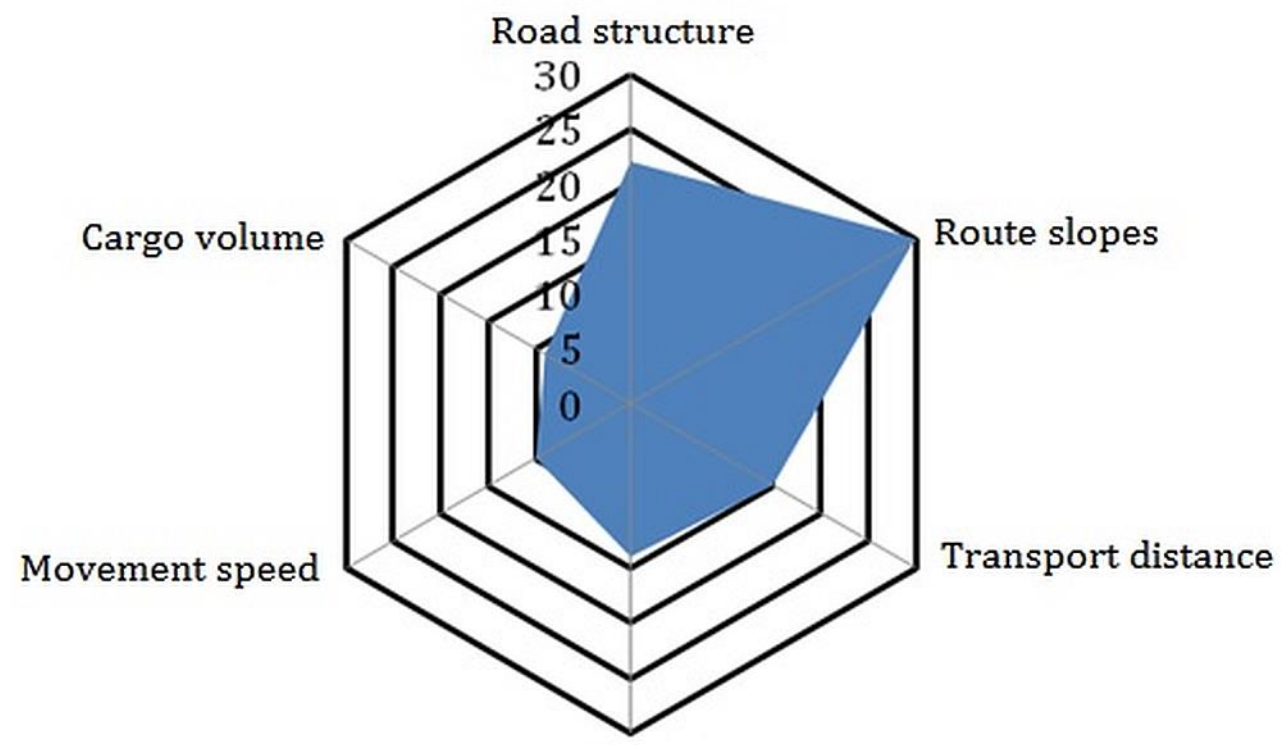

Vehicle condition

Fig. 2. The influence of operation of technical and technological factors on the energy intensity of transportation (percentage)

Figure 2 illustrates that variation in the slopes of the route has the greatest influence on the change in energy intensity. The main thing in this case is the longitudinal angle of inclination of the technological road in relation to the transverse one.

An analysis of the operating modes and operating parameters of open-pit vehicles allowed to establish that the operation of dump trucks in satisfactory conditions will reduce the specific energy costs for transporting the blasted rock mass by 10-12\% (Table 1).

Table 1. Matrix of influence of operating parameters and operating modes on the specific energy consumption

\begin{tabular}{|c|c|c|c|}
\hline & \multicolumn{2}{|c|}{ Working hours (driver qualification) } \\
\hline & & Satisfactory & Unsatisfactory \\
\hline \multirow{6}{*}{ 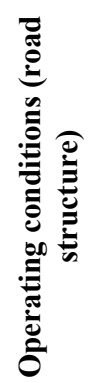 } & \multirow{3}{*}{ 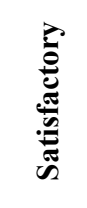 } & Certified $^{*}-0.95$ & Not certified $^{*}-1.1$ \\
\hline & & Allowed $V_{\mathrm{hs}}(40-50 \mathrm{~km} / \mathrm{h})-0.95$ & Allowed $V_{\mathrm{hs}}(40-50 \mathrm{~km} / \mathrm{h})-0.95$ \\
\hline & & $K_{P}^{* *}=0.95 \times 0.95=0.9$ & $K_{P}=1.1 \times 0.95=1.05$ \\
\hline & \multirow{3}{*}{ 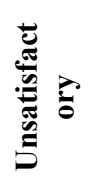 } & Certified $^{*}-0.95$ & Not certified ${ }^{*}-1.1$ \\
\hline & & Allowed $V_{\mathrm{hs}}(20-30 \mathrm{~km} / \mathrm{h})-1.15$ & Allowed $V_{\mathrm{hs}}(20-30 \mathrm{~km} / \mathrm{h})-1.15$ \\
\hline & & $K_{P}=0.95 \times 1.15=1.09$ & $K_{P}=1.1 \times 1.15=1.27$ \\
\hline
\end{tabular}

* - the driver's reaction time and the degree of decisions rationality made during transportation

** - express coefficient that allows to estimate the change in the specific energy consumption (with the $\operatorname{standard} K_{P}=1$ ) 
The structure of a technological road has significant impact on energy costs: the number and scale of ascents / descents, the number of crossings and turns, and the condition of the roadway. In the case of significant deviations from the norms and rules in the operation of the road, firstly, the probability of repair work increases, the resource of various machine systems decreases, the cost of fuel and lubricants increases, and so on.

All other factors must also be taken into account to estimate costs. However, the greatest changes in the structure of an open-pit dump truck occur when they are combined.

In this regard, it is possible to divide any route of transportation of the exploded rock mass into energy-saving and energy-consuming sections.

Energy saving stages of transportation include loading and unloading, waiting for loading, changing shifts, and a lunch break. At these stages, there is no movement of the dump truck, the engine is idling, and therefore, there is no significant energy consumption.

The main influence on the energy intensity of the process of transportation by dump trucks and the resource of metal structures is at the operation energy-consuming stages. These include the movement of the car on straight technological roads, ascents and descents, turns and when driving through crossings [14].

As a criterion for assessing the energy efficiency of transport systems of deep open-pits, the value of specific energy costs was adopted, which was determined by the formula [6]

$$
P_{\mathrm{f}}=\frac{Q}{i m l} k_{\mathrm{proc}} k_{\mathrm{sh}} k_{\mathrm{ex}}
$$

where $P_{\mathrm{f}}$ is the cost per unit of energy of transporting 1 ton of rock mass per $1 \mathrm{~m}$, g. u.t./t•m (gram of standard fuel/t•m); $Q$ - is the diesel fuel consumption, $\mathrm{g} ; m-$ is the weight of the transported cargo, $\mathrm{t} ; l-$ is the distance of transportation, $\mathrm{m} ; i-$ is the slope of the route, $\%$; $k_{\text {proc }}-$ is the coefficient of processing, which takes into account the energy cost of obtaining diesel fuel from oil $\left(k_{\text {proc }}=1.18 \div 1.20\right) ; k_{\mathrm{ex}}$ is the coefficient, which takes into account the energy cost of extracting and transporting fuel $\left(k_{\mathrm{ex}}=1.04 \div 1.10\right) ; k_{\mathrm{sh}}-$ coefficient that takes into account the difference in the specific heat of combustion of diesel and standard fuel $\left(k_{\mathrm{sh}}=1.5\right)$.

Formula (1) takes into account the influence of various factors on energy intensity as much as possible. The same indicators are taken into account when calculating technical and economic indicators.

In [3], the relationship between the specific energy consumption from the longitudinal slope of the route was established when ranking BelAZ mining dump trucks into three groups by load capacity:

$$
\begin{aligned}
& \text { to } 55 \mathrm{t} \rightarrow P_{f}^{55}=0.0005 i^{2}+0.07 i+1.01 ; \\
& \text { from } 55 \mathrm{t} \text { to } 130 \mathrm{t} \rightarrow P_{f}^{130}=0.0004 i^{2}+0.04 i+2 ; \\
& \text { from } 130 \mathrm{t} \text { to } 320 \mathrm{t} \rightarrow P_{f}^{320}=0.00038 i^{2}+0.008 i+3 .
\end{aligned}
$$

Open pit dump trucks which are operated in the conditions of the developed mineral deposit, is advisable to distribute due to the value of the longitudinal slope of the technological route (Fig. 3). 


\begin{tabular}{|c|c|c|}
\hline \multicolumn{3}{|c|}{ Route inclination on the rise } \\
\hline$\downarrow$ & $\downarrow$ & $\downarrow$ \\
\hline$\leq 50 \%$ & $50-80 \%$ & $\geq 80 \%$ \\
\hline$\downarrow$ & $\downarrow$ & $\downarrow$ \\
\hline \multicolumn{3}{|c|}{ dump truck models } \\
\hline$\downarrow$ & $\downarrow$ & $\downarrow$ \\
\hline$\leq 55$ tons & $55-130$ tons & $\geq 130$ tons \\
\hline$\downarrow$ & $\downarrow$ & $\downarrow$ \\
\hline \multicolumn{3}{|c|}{ transportation point } \\
\hline$\downarrow$ & $\downarrow$ & $\downarrow$ \\
\hline $\begin{array}{c}\text { face } \rightarrow \text { dump } \\
\text { face } \rightarrow \text { temporary } \\
\text { warehouse dump } \rightarrow \\
\text { dump } \\
\text { warehouse dump } \rightarrow \\
\text { temporary }\end{array}$ & $\begin{array}{c}\text { face } \rightarrow \text { dump } \\
\text { face } \rightarrow \text { temporary } \\
\text { face } \rightarrow \text { warehouse } \\
\text { dump }\end{array}$ & $\begin{array}{c}\text { face } \rightarrow \text { warehouse } \\
\text { dump }\end{array}$ \\
\hline
\end{tabular}

Fig. 3. The scheme of distribution of dump trucks of different load capacities depending on the slope of the route on the rise

As Figure 3 shows, if it is necessary to transport rock mass at great depths, it is necessary to use heavy dump trucks. The issue of economic assessment of energy distribution is relevant.

\subsection{Methods for assessing the economic performance of dump trucks}

The economic performance of motor transport is determined by the type of a dump truck, its load capacity, the volume of blasted rock mass transported and the distance of transportation, as well as the system of work organization.

According to the methodology presented in the works of Sheshko E. E., the assessment of technical and economic indicators is made at the given costs:

$$
\mathrm{P}=\mathrm{EK}+\mathrm{C}
$$


where $\mathrm{P}$ is the reduced cost of operating vehicles, rubles; $\mathrm{E}$ - is the coefficient of economic efficiency of capital investments; $\mathrm{K}$ - is the capital cost of motor transport, rubles; $\mathrm{C}$ - is the operating cost, rubles.

In turn, the capital costs are

$$
\mathrm{K}=\mathrm{K}_{\mathrm{cr}}+\mathrm{K}_{\mathrm{rr}}+\mathrm{K}_{\mathrm{c}}+\mathrm{K}_{\mathrm{t}}+\mathrm{K}_{\text {main }}+\mathrm{K}_{\mathrm{m}}
$$

where $K_{c r}$ - is the cost of construction of the road bed, rub; $K_{r r}-$ is costs for the construction of road revetment, rub; $K_{c}-$ is the costs for the construction of buildings and structures for the maintenance and repair of rolling stock, rub; $K_{t}$ - is the cost of the dump truck, $\mathrm{rub} ; \mathrm{K}_{\mathrm{c}}-$ is the cost of equipment for road maintenance, rub; $\mathrm{K}_{\mathrm{m}}-$ is the cost of equipment for vehicles operation management, rub.

The formula for calculating operating costs is the following:

$$
\mathrm{C}=\mathrm{C}_{\mathrm{r}}+\mathrm{C}_{\text {maim }}+\mathrm{C}_{\mathrm{s}}+\mathrm{C}_{\mathrm{f}}+\mathrm{C}_{\mathrm{d}}+\mathrm{C}_{\mathrm{m}}
$$

where $\mathrm{C}_{\mathrm{r}}$ - is costs for maintenance and repair of roads, rub; $\mathrm{C}_{\text {main }}$ - is maintenance costs of the service of operation and repair of dump trucks, rub; $\mathrm{C}_{\mathrm{s}}$ - is drivers' salary costs, rub; $C_{f}$ - is fuel cost, rub; $C_{d}-$ is depreciation expense, rub; $C_{m}-$ is cost of maintenance of the vehicle management system, rub.

The calculation of the carrier cost by motor transport currently shows that $25-30 \%$ is depreciation expense, $20-24 \%$ - is drivers' salary, 20-25\% - is tire repairs, $12-14 \%$ - is car repairs, $6-11 \%$ - is fuel costs.

Taking into account the economic assessment of the operation of dump trucks, it is necessary to take into account the direct losses from the downtime of open-pit vehicles (rub/working hour), which are calculated according to the well-known formula:

$$
\mathrm{P}_{\mathrm{pr}}=\frac{\mathrm{C}_{\mathrm{tr}} \mathrm{P}_{\mathrm{d}} \mathrm{S}_{\mathrm{semi}}}{\mathrm{T}_{\mathrm{f}}}
$$

where $\mathrm{C}_{\mathrm{tr}}$ - is the cost of transportation, rub/tkm; $\mathrm{P}_{\mathrm{d}}$ - is average monthly performance of the dump truck, tkm; $\mathrm{S}_{\text {semi }}$ - share of semi-fixed costs, $\% ; \mathrm{T}_{\mathrm{f}}-$ is the number of working hours per month, working hours.

According to the monitoring of the operation of BelAZ dump trucks of various load capacities, it was found that the change in the value of direct losses from downtime of heavy dump trucks depends on various factors (Table 2).

Table 2. The significance of various factors on the change in direct losses from downtime

\begin{tabular}{|c|c|c|}
\hline \multirow{2}{*}{$\begin{array}{c}\text { INFLUENCE } \\
\text { CATEGORY }\end{array}$} & FACTOR & $\begin{array}{c}\text { THE DEGREE OF } \\
\text { SIGNIFICANCE }\end{array}$ \\
\hline \multirow{3}{*}{$\begin{array}{c}\text { Maintenance and repair } \\
\text { strategy }\end{array}$} & Operational life & 14 \\
\cline { 2 - 3 } & Repair characteristics & 9 \\
\cline { 2 - 3 } & Quality of spare parts & 8 \\
\cline { 2 - 3 } Mining and Technical & Staff qualifications & 12 \\
\cline { 2 - 3 } & Structure of working areas \\
& $\begin{array}{c}\text { State and profile of technological } \\
\text { roads }\end{array}$ & 15 \\
\hline \multirow{2}{*}{ Organizational } & $\begin{array}{c}\text { Organization of the loading and } \\
\text { transport process }\end{array}$ & 13 \\
\cline { 2 - 3 } & Driving modes & 10 \\
\hline Climatic & Environmental parameters & 10 \\
\hline
\end{tabular}


The data presented in Table 2 illustrates that the economic losses during the operation of dump trucks are most affected by the state of roads and mining machinery.

\subsection{Analysis of the obtained results}

In the period from 2018 to 2020, the work of heavy dump trucks "BelAZ" (BelAZ-7555, BelAZ-75130, BelAZ-75306) was monitored at the open-pits of Kuzbass. To analyse the economic assessment of the energy efficiency of dump truck distribution in the conditions of an open-pit, data, that were used to calculate direct losses from dump truck downtime (6) and specific energy costs were obtained (1).

During the period under review, the number of working hours per month were 480, and the share of semi-fixed costs varied from 25 to $30 \%$. Therefore, formula 6 can be transformed in the following way:

$$
\mathrm{P}_{\mathrm{pr}}=0.625 \mathrm{C}_{\mathrm{tr}} \mathrm{P}_{\mathrm{d}} \text {. }
$$

The cost of transportation corresponds to the operating costs (5). The components of the formula depend on the mining and technological conditions of the deposit, as well as on the machine condition. For a representative sample, cars were selected that were operated in similar conditions and their mileage was close to identical. The cost of transporting the blasted rock mass by heavy dump trucks was accepted according to the research of Ya. O. Litvin [1].

According to the analysis results, the dependences of the direct losses of dump trucks on the longitudinal slopes of the route were obtained (Fig. 4).

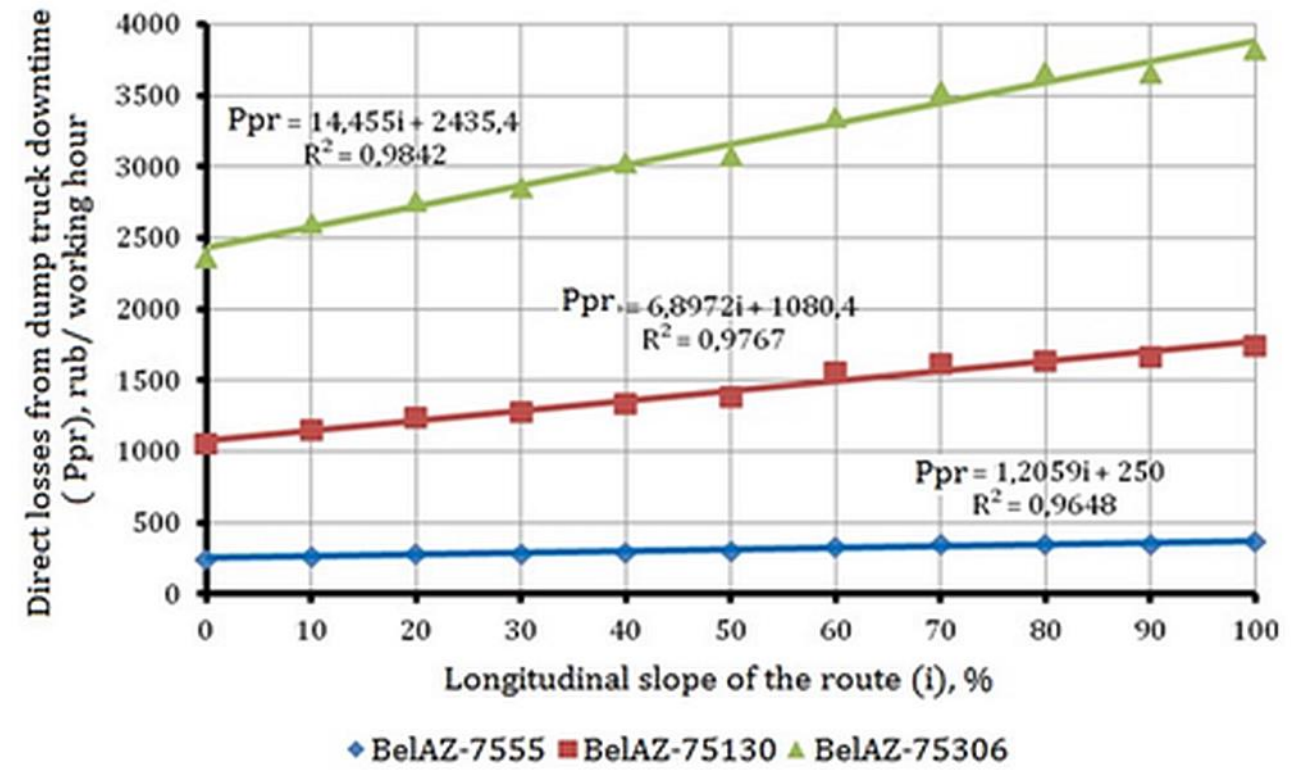

Fig. 4. The influence of the value of the longitudinal slope of the route on the change in direct losses from downtime of open-pit vehicles

As Fig. 4 shows, the dependence of direct losses on the longitudinal angle of inclination of the technological road takes a linear character with sufficiently high approximation coefficients for each dump truck model. Consequently, the obtained equations allow to predict direct losses on roads with longitudinal slopes above $100 \%$. 
Based on the obtained results, graphics of the relationship between direct losses from downtime and specific energy costs for BelAZ-7555, BelAZ-75130 and BelAZ-75306 dump trucks were constructed (Fig. 4).

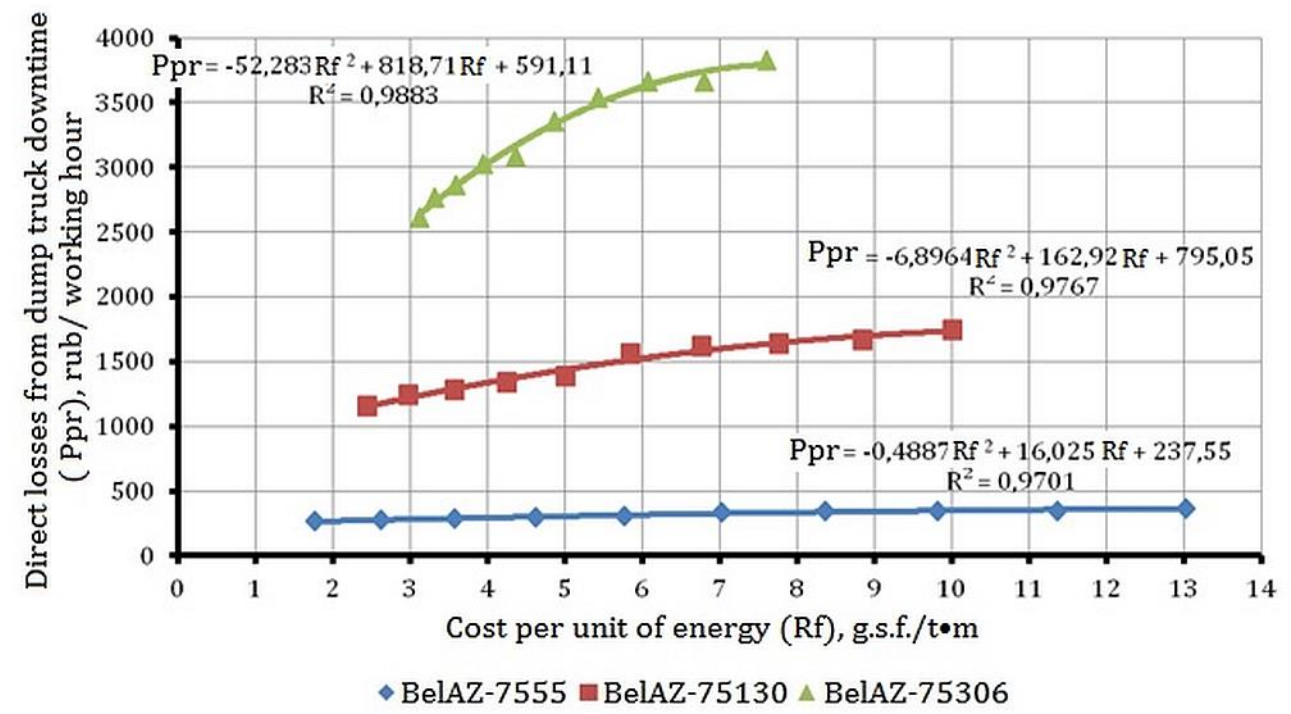

Fig. 5. The relationship between the value of direct losses from downtime of open-pit vehicles and specific energy costs

Figure 5 illustrates that the relationship between two economic and energy indicators is determined by polynomial dependencies with sufficiently high approximation coefficients for each dump truck model.

\section{Conclusion}

The operation of open-pit vehicles in the conditions of a developed deposit is a system of costly processes that are reflected both in the loss of energy and other resources. An important point for production has always been and still is the economic assessment of the heavy dump trucks usage, which is based on the rational distribution of mining machines in complex cycles.

The economic assessment of the energy distribution of open-pit dump trucks in the conditions of an open pit allows predicting the efficiency of motor transport in terms of both specific energy costs and economic losses. The obtained dependences allow taking into account the maximum number of necessary parameters and factors that affect the positive economic and energy effects of operation when distributing dump trucks in a complex cycle.

\section{References}

1. I.V. Kuznetsov, I.A. Panachev, G.M. Dubov, S.A. Nohrin, Handbook. An Engineering journal, 4, 19 (2019)

2. Baoying Fan, Yingju Yuan, International Journal of Mining Science and Technology, 26, 653, 2016 
3. Panachev I. A., Shirokolobov G. V., Kuznetsov I. V., Shirokolobova A. G., The 8th Russian-Chinese Symposium. Coal in the 21st Century: Mining, Processing and Safety, 144 (2016)

4. A. Soofastaei, S.M. Aminossadati, M.S. Kizil, P. Knights, International Journal of Mining Science and Technology, 26, 745, (2016)

5. G.M. Dubov, D.S. Trukhmanov, I.V. Kuznetsov, S.A. Nokhrin, A.N. Sergel, E3S Web Conf., 105, 03018 (2019)

6. G.M. Dubov, D.S. Trukhmanov, I.V. Kuznetsov, S.A. Nokhrin, A.N. Sergel, E3S Web Conf., 105, 03019 (2019)

7. S.S. Azikhanov, A.R. Bogomolov, G.M. Dubov, S.A. Nokhrin, MATEC Web of Conferences, 297, 03001 (2019)

8. Chengguo Zhang, Ismet Canbulat, Faham Tahmasebinia, Bruce Hebblewhite, International Journal of Mining Science and Technology, 27, 43, (2017)

9. Fukun Xiao, Gang Liu, Ze Zhang, Zhiliang Shen, Fengrui Zhang, Yifei Wang, International Journal of Mining Science and Technology, 26, 981, (2016)

10. Jingdong Jiang, Quansheng Liu, Jie Xu, International Journal of Mining Science and Technology, 26, 1003, (2016)

11. Jesse W. Puller, Ken W. Mills, Rob G. Jeffrey, Rick J. Walker, International Journal of Mining Science and Technology, 26, 103, (2016)

12. G.M. Dubov, D.S. Trukhmanov, S.A. Nokhrin, A.N. Sergel, MATEC Web of Conferences, 297, 03002 (2019)

13. Method for installing cryogenic fuel tanks on a mining dump truck, Patent RU № 2701133, 2019, bulletin №27, S.A. Nohrin, G.M. Dubov, D.S. Trukhmanov

14. I.V. Kuznetsov, I.A. Panachev, G.M. Dubov, S.A. Nohrin, E3S Web Conf., 174, 03010 (2020)

15. G.M. Dubov, D.S. Trukhmanov, A.A. Chegoshev, V.E. Ashikhmin, E3S Web Conf., 41, 03008 (2018) 